\title{
Contraception Knowledge And Risky Sexual Behavior In College Students
}

Marta Yubero, University of Castilla-La Mancha, Spain

Elisa Larrañaga, Ph.D., University of Castilla-La Mancha, Spain

\begin{abstract}
Most research indicates that there is an early beginning of sexual relations among young people, a fact that makes them susceptible to risky practices as it is demonstrated by the growing percentage of unwanted pregnancies and the rate of IVES among youngsters under 18 years old. Information and education on sexual health are of relevant importance for the prevention of a risky sexual behavior among young people. In previous studies it has been demonstrated that there is a significant lack of knowledge regarding contraceptive methods too. The current work aims at learning about the sexual behaviors of young people as well as about the basic knowledge they should have about contraceptive methods so as to elaborate efficient intervention and prevention programs. The participants were between 17 and 23 years old. Their first sexual relations were at 16.5 years old, as an average, a figure that is coincident with that of other studies. $85 \%$ of the college students being surveyed had had complete sexual relations. Among them, a significant percentage had a risky sexual behavior. Regarding the knowledge they have of contraceptive methods, there is no significant difference between genders. There is lack of knowledge of essential aspects of this area.
\end{abstract}

Keywords: Risky Sexual Behavior; Contraception Knowledge; College Students

\section{INTRODUCTION}

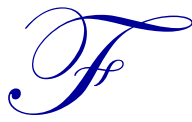

rom the social point of view, the high rate of unwanted pregnancies among adolescents and young women is a cause of concern. It is a need of public health to get to know about the risky sexual behavior of young people in order to start adequate prevention campaigns. Young people are considered a segment that is susceptible of being involved in risky sexual practices. Among the main risky factors we have: an early start in sexual relations; having intercourse under the effect of alcohol and attitudes that become more and more liberal.

Research indicates that there is an early start of sexual relations (Calafat, Juan, Becoña, Mantecón, \& Ramón, 2009) and that during the first experiences, adolescents tend not to use efficient contraceptive methods for the prevention of unwanted pregnancies (Navarro, Carrasco, Sánchez, \& Torrico, 2004). Every year the number of pregnancies among young people continue increasing (Chia-Chen, Thompson, \& Morrison-Beedy, 2010). In Spain from 2001 to 2008, the number of unwanted pregnancies in girls under 15 years old has gone up in a $76 \%$.

The studies have shown that in recurrent way adolescents and young people of both genders do not use prophylactics with the expected frequency, thus, creating the proper conditions for pregnancy and sexuallytransmitted diseases (Piña, Lozano, Vázquez, \& Carrillo, 2010). The data reflects that the low consistency in the use of contraceptives causes the high rates of unwanted pregnancies at these ages, as well as the voluntary interruptions of such pregnancies (Plá, 2008). There are differences in the sexual behaviors depending on gender, though. Boys usually start sexual practices earlier than girls and have more occasional partners (García-Vega, Menéndez, García, \& Rico, 2010).

Even though the factors that influence that people are involved in risky sexual behavior have been broadly investigated (Teva, Bermúdez, \& Buela-Casal, 2011), more studies are needed regarding the factors that are related 
directly with such risky behavior among young people. We are interested in learning about the risky sexual behavior, the contraceptive knowledge and attitudes college students have regarding the use of contraceptives. The objective is to be able to carry out intervention proposals that have a direct action on the problems young people have when carrying out risky sexual behaviors.

\section{METHODOLOGY}

It is a descriptive study carried out through surveys. The date we present goes in accordance with the pilot study. the sample is composed of 123 young people, students of Universidad de Castilla-La Mancha, with ages between 17 and 23 years old. Women are the $73 \%$.

In order to gather the necessary information, we made use of a questionnaire on sexual behavior. The data we are presenting deals with two main sectors: risky sexual behavior and knowledge about contraceptives. The first part is constituted by items coming from the research of Navarro et al, (2004) and of Teva, Bermudez and BuelaCasal (2009) which analyzed the sexual behavior among adolescents. For the research on the knowledge about contraceptive methods, we were based on the study of Calafat et al (2009).

The variables that were analyzed in the current study are:

- $\quad$ Risky sexual behavior and the use of contraceptive methods: experience of having had intercourse with penetration; age of the first sexual experience; contraceptive methods used and present contraceptive method being used, as well as the use of emergency contraceptive methods and the consumption of alcohol.

- Basic knowledge about contraception: this sector is composed of a series of affirmations about beliefs and basic knowledge of contraception. The participant had to say whether these statements were true or false.

The participants did so in a voluntary way, after being explained of the objective of the study. After asking for the consent of the classrooms' teachers, the questionnaires were handed to the students.

\section{RESULTS}

Has had intercourse with penetration the $83.9 \%$. In Chart 1 , the percentage is greater in men than in women $\left(\chi^{2}=4.74, p<.029\right)$.

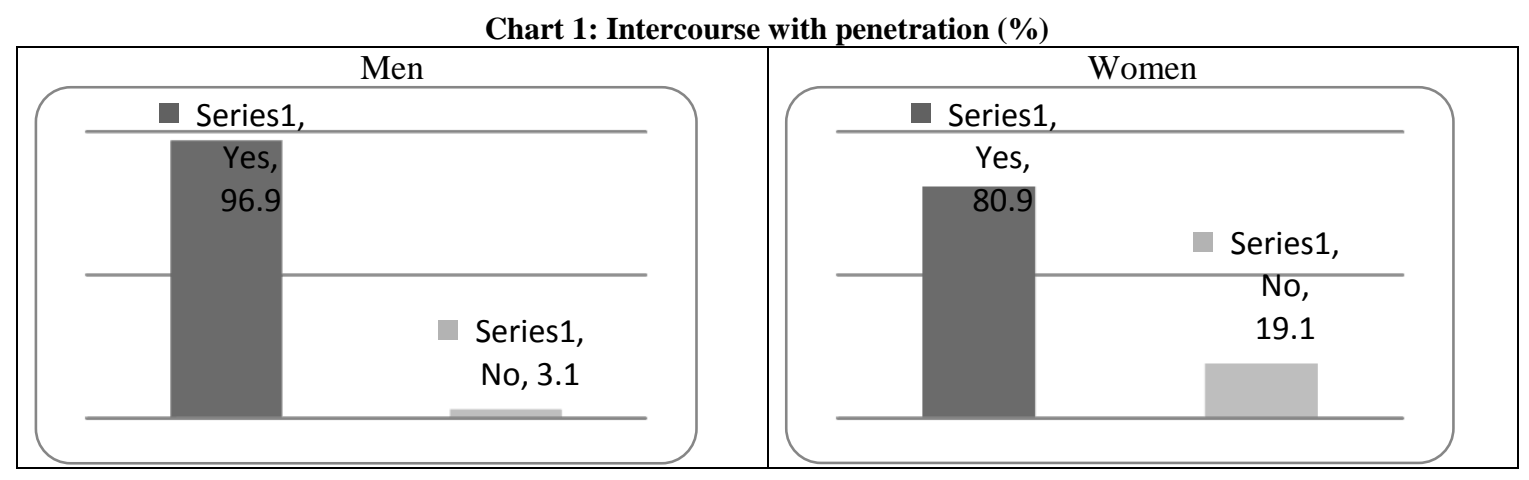

Mostly, they have had their first sexual relation between the ages of 14 and 18, being the average of 16.56 years old $(S D=2.97)$. Women start with the same age $(M=16.4)$ as men $(M=16.8)$. There was no statistical significance in the difference $(t=0.51 . p=.614)$.

In the majority of the cases, the first sexual relation takes place with a stable couple (73.1\%), and using protection (94.7\% with prophylactics) and with no consumption of alcohol. However, a $26.9 \%$ had had a first sexual relation with an occasional couple. The profile of this relation is with the consumption of alcohol (42.9\%), even though $85.7 \%$ reports that they did use a prophylactic. More than $70 \%$ of the surveyed women indicate that the decision of having the first intercourse was taken by the man. A 30.7\% used an emergency contraception after their first sexual relation. 
The use of contraceptives in the current relations constitutes a profile of pregnancy risk: $8.5 \%$ does not use any metho;.11.3\% uses coitus interruptus; $18.3 \%$ takes pills, but a $7.7 \%$ considers that there is no risk of pregnancy if one pill is skipped. $77.5 \%$ uses a prophylactic but $33 \%$ states that they do so only during ejaculation. Only $2.8 \%$ uses vaginal rings.

The situation is different depending on whether they have a stable couple or not. Almost $77 \%$ does have a couple. Most of them (95\%) have relations with penetration. 60\% uses a prophylactic and $25 \%$ take contraceptive pills. However $10 \%$ does not use any method and 5\% makes use of coitus interruptus. Half of them consider it a safe method. It is important to emphasize that 40 reports having used an emergency contraceptive in some occasion. 23\% does not have a couple. Half of them have relations with penetration. 50\% of them use prophylactics and $17.7 \%$ takes the pill. $11 \%$ of the young college students have sexual relations with no protection at all. $22 \%$ of them say the only method they use is coitus interruptus.

The results of the items regarding knowledge (Table 1) indicate important deficiencies on sexual information.

Table 1: Sexual Knowledge (\%)

\begin{tabular}{|l|c|c|c|c|}
\hline & \multicolumn{2}{|c|}{ Men } & \multicolumn{2}{c|}{ Women } \\
\cline { 2 - 5 } & T & F & T & F \\
\hline Prophylactis are safe if they are used before ejaculation & 62.5 & 37.5 & 61.3 & 29.0 \\
\hline Coitus interruptus is a safe method to avoid pregnancy & 25 & 75 & 3.2 & 96.8 \\
\hline It is not possible to be pregnant in the first intercourse & 12.5 & 87.5 & 0 & 100 \\
\hline Alcohol improve sexual relations & 0 & 100 & 0 & 100 \\
\hline Before starting hormonal contraception, it is better to get medical checkups & 100 & 0 & 96.8 & 3.2 \\
\hline Alcohol reduces the effectiveness of oral contraception & 75 & 25 & 48.4 & 48.4 \\
\hline If you skip taking one dose of the oral contraceptive there is a risk of pregnancy & 100 & 0 & 93.5 & 6.5 \\
\hline Emergency contraception methods can be used only during the first 24 hours & 100 & 0 & 54.8 & 45.2 \\
\hline You need a medical prescription to buy contraceptives & 12.5 & 87.5 & 16.1 & 63.9 \\
\hline The minimum age to take contraceptives is of 18 & 12.5 & 87.5 & 3.2 & 96.8 \\
\hline He/she is adequately informed & \multicolumn{2}{|c|}{74.2} & 83.9 \\
\hline
\end{tabular}

If we transfer these results to a scale of 10 points, $2.5 \%$ of the young people would fail. A $7.7 \%$ would pass. A $64.1 \%$ would get between 7 and 9 points and only $17.9 \%$ would get the maximum of 10 . But the greatest concern is that under 7 points all of them consider they are adequately informed, while in fact only those getting 10 points are. $20 \%$ of the latter consider they still need to be better informed and almost have of the outstanding.

\section{CONCLUSIONS}

Coincident with other studies, findings say that sexual relations with penetration start during adolescence (Bermúdez, Castro, Madrid, \& Buela-Casal, 2010; Teva, Bermúdez, \& Buela-Casal, 2009). Data indicate that there are less and less differences among men and women in regard to the initiation of sexuality.

The contraceptive method young people use more frequently is the prophylactic. Following the same results of the college students of the work of Muñoz-Silva, Sánchez-García, Martins, and Nunes (2009), the use of prophylactics is higher when done with a stable partner. The percentage of women taking the contraceptive pill is relevant too.

There are risky sexual behaviors during the first sexual relations and they increase in the stable relations. The risky behaviors are high and a matter of concern if we take into account that an important percentage of young people do not use any protection method and those who use it in an important percentage do it in an erroneous way

Regarding knowledge, young people have sexual bias. Even more, the young people who lack more knowledge are precisely the ones that consider themselves better informed. We confirm the lack of knowledge regarding contraceptive methods and the need to implement efficient programs of sexual education. 
Sexual education is more and more necessary among those young people who seem to be well informed but who, in fact, are rather lacking it, especially in topics of contraception and risky sexual behaviors. The continuity in the transmission of certain myths and the ignorance on basic topics of contraception and risky sexual behaviours prove that the affective-sexual education of our young people is not being learn appropriately. We have to ask ourselves how to transmit it in the best possible way and in proper time. We are to decide whether such an education should begin earlier in life (Cordón-Colchón, 2009).

Young people have the right to an effective sexual education, as stated by González, Sánchez-Crespo and González (2009), a quality information and sexual education can provide them with the necessary knowledge, capacities and attitudes that are necessary for the process of making well-informed decisions nowadays and in the future.

\section{AUTHOR INFORMATION}

Marta Yubero, Degree in Medicine by University of Castilla-La Mancha. Doctoral student of Social and Health Care Research Center of Cuenca, University of Castilla-La Mancha (Spain). Research Interest: Sexual behavior and prevention sexual risk. Phone +34 902204 100; Fax +34 902204 130; E-mail: Marta.Yubero@alum.uclm.es

Elisa Larrañaga, Ph.D. in Psychology by University of Castilla-La Mancha and Degree in Psychology by University Autónoma of Madrid. Associate Professor in Psychology Department. Faculty of Social Work of Cuenca, University of Castilla-La Mancha (Spain). Research Interest: Process psyco-socials of education. Phone +34 902 204 100; Fax +34 902204 130; E-mail: Elisa.Larranaga@uclm.es (Corresponding author)

\section{REFERENCES}

1. Bermúdez, M.P., Castro, A., Madrid, J., and Buela-Casal, G. (2010): “Análisis de la conducta sexual de adolescentes autóctonos e inmigrantes latinoamericanos en España". International Journal of Clinical and Health Psychology, 10 (1), 89-103.

2. Calafat, A., Juan, M., Becoña, E., Mantecón, A., and Ramón, A. (2009): "Sexualidad de riesgo y consumo de drogas en el contexto recreativo. Una perspectiva de género". Psicothema, 21 (2), 227-233.

3. Chia-Chen, A, Thompson, E., and Morrison-Beedy D. (2010): "Multi-system influences on adolescent risky sexual behavior". Research in Nursing and Health, 33, 512-526.

4. Cordón-Colchón, J. (2009): "Mitos y creencias sexuales de una población adolescente en Almendralejo". Matronas Profesión, 9 (3), 6-12.

5. García-Vega, E., Menéndez, E., García, P., and Rico, R. (2010): "Influencia del sexo y del género en el comportamiento sexual de una población adolescente". Psicothema, 22 (4), 606-612.

6. González, C., Sánchez-Crespo, J., and González, A. (2009): "Educación integral en sexualidad y anticoncepción para jóvenes". Enfermería Clínica, 19 (4), 221-224.

7. Muñoz-Silva, A., Sánchez-García, M., Martins, A. and Nunes, C. (2009): "Gender differences in HIVRelated sexual behavior among college students from Spain and Portugal”. The Spanish Journal of Psychology, 12 (2), 485-495.

8. Navarro Y, Carrasco A, Sánchez J, and Torrico E (2004): “Comportamiento y actitudes sexuales en adolescentes y jóvenes". Archivos Hispanoamericanos de Sexología, 10 (2), 168-182

9. Piña, J., Lozano, D.I., Vázquez, P. and Carrillo, I.C. (2010): "Motivos y uso de preservativo en estudiantes universitarios de Ciudad Juárez (México)". Anales de Psicología, 26 (1), 18-26.

10. Plá, E. (2008): "Principales datos sobre embarazos, interrupción voluntaria de embarazos y anticoncepción en la adolescencia". Revista de Pediatría de Atención Primaria, 2, 79-82.

11. Teva, I., Bermúdez, M.P. and Buela-Casal, G. (2009): "Characteristics of sexual behavior in Spanish adoelscents". The Spanish Journal of Psychology, 12 (2), 471-484.

12. Teva, I., Bermúdez, M.P., and Buela-Casal, G. (2011): "Búsqueda de sensaciones sexuales, estilos de afrontamiento, estrés social y su relación con la conducta sexual adolescente". Anales de Psicología, 27 (1), $35-46$. 